\title{
Generation of diploid Pichia pastoris strains by mating and their application for recombinant protein production
}

Ming-Tang Chen", Song Lin, Ishaan Shandil, Dewan Andrews, Terrance A Stadheim and Byung-Kwon Choi ${ }^{*}$

\begin{abstract}
Background: Yeast mating provides an efficient means for strain and library construction. However, biotechnological applications of mating in the methylotrophic yeast Pichia pastoris have been hampered because of concerns about strain stability of $P$. pastoris diploids. The aim of the study reported here is to investigate heterologous protein expression in diploid $P$. pastoris strains and to evaluate diploid strain stability using high cell density fermentation processes.

Results: By using a monoclonal antibody as a target protein, we demonstrate that recombinant protein production in both wild-type and glycoengineered P. pastoris diploids is stable and efficient during a nutrient rich shake flask cultivation. When diploid strains were cultivated under bioreactor conditions, sporulation was observed. Nevertheless, both wild-type and glycoengineered P. pastoris diploids showed robust productivity and secreted recombinant antibody of high quality. Specifically, the yeast culture maintained a diploid state for $240 \mathrm{~h}$ post-induction phase while protein titer and N-linked glycosylation profiles were comparable to that of a haploid strain expressing the same antibody. As an application of mating, we also constructed an antibody display library and used mating to generate novel full-length antibody sequences.
\end{abstract}

Conclusions: To the best of our knowledge, this study reports for the first time a comprehensive characterization of recombinant protein expression and fermentation using diploid $P$. pastoris strains. Data presented here support the use of mating for various applications including strain consolidation, variable-region glycosylation antibody display library, and process optimization.

Keywords: Mating, Diploid, Pichia pastoris, Strain stability, Fermentation, Recombinant protein expression

\section{Background}

The methylotrophic yeast $P$. pastoris has become an increasingly popular host for recombinant protein expression in recent times. As a eukaryote, $P$. pastoris has the capability to perform various post-translational modifications such as glycosylation, disulphide isomerization, proteolytic processing, and secretes correctly folded protein into culture media. P. pastoris can grow in methanol to very high cell densities in bioreactors, exceeding $450 \mathrm{~g} / \mathrm{L}$ wet cell weight (WCW). Being an obligate aerobe when fed with methanol, $P$. pastoris does not switch to anaerobic metabolism that would lead to toxic

\footnotetext{
* Correspondence: ming-tang.chen@merck.com;

byung-kwon.choi@merck.com

GlycoFi, Biologics Discovery, Merck Research Laboratories, Merck \& Co., Inc,

21 Lafayette Street, Suite 200, Lebanon, NH 03766, USA
}

metabolite accumulation under oxygen limited condition. This makes it possible to run high cell density fermentations under dissolved oxygen controlled processes.

Other benefits of the P. pastoris system include ease of genetic manipulation, stable expression, rapid cell growth, low-cost scalable fermentation processes and little to no risk of human pathogenic virus contamination. The $P$. pastoris system has been successfully used to produce a wide variety of heterologous proteins [1]. Fermentation titers at grams per liter scale have been reported for several target proteins including full-length antibodies [2-6].

In yeasts, the outer oligosaccharide chains of secreted proteins are decorated with high mannose type glycans. P. pastoris-derived glycosylated proteins are therefore potentially immunogenic. To overcome this issue, we

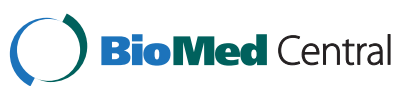


pioneered a glycoengineered humanized $P$. pastoris expression system that could produce glycoproteins with glycosylation profiles similar to mammalian systems [7-13]. Therapeutic glycoproteins produced by the humanized $P$. pastoris platform have shown comparable folding, stability, and in vitro and in vivo efficacies in preclinical models to their counterparts produced from the $\mathrm{CHO}$ platform [14-16].

Like $S$. cerevisiae, $P$. pastoris is an ascomycetous homothallic budding yeast that can exist in both haploid and diploid states. Most industrial yeasts are diploids or polyploids. Diploid S. cerevisiae strains are generally considered to have greater thermo-stability as well as a higher tolerance to acid, ethanol, and other fermentation inhibitors than haploid strains $[17,18]$. Breeding polyploid industrial yeast strains has been shown to improve ethanol productivity and protein production [19]. Moreover, mating of $S$. cerevisiae has been successfully employed in other biotechnology and discovery applications such as yeast two-hybrid libraries [20] and antibody Fab display libraries [21]. In the case of an antibody Fab mating library, small variable heavy and light chain libraries are built and transformed separately into two haploid yeast strains with opposite mating types. Through mating of heavy and light chain haploid libraries, a large combinatorial Fab library can be generated and displayed on the diploid yeast surface [21].

One of the major differences distinguishing $P$. pastoris and $S$. cerevisiae mating is that $P$. pastoris is most stable in the vegetative haploid state and remains haploid unless forced to mate under certain conditions such as nitrogen limited-starvation [22]. The mated diploid yeasts efficiently undergo meiosis, sporulation, and switch back to the haploid state upon nitrogen limitation and other nutritional stresses. Due to the concern about diploid stability, especially in bioreactor fermentation processes, until now, no strategies have been described to utilize, much less to comprehensively quantify, recombinant protein expression and fermentation using diploid $P$. pastoris strains.

By using an IgG1 monoclonal antibody as the target protein, here, we demonstrate that both wild-type and glyco-engineered $P$. pastoris diploids provide stable and efficient heterologous protein expression in a nutrient rich shake flask environment. When the diploid strains were run in simple fed-batch, carbon-limited fermentation processes, both wild-type and glyco-engineered diploid strains afforded high protein productivity for at least 240 hours post-induction. Despite the observation of sporulation events happening during fermentation, we provide evidence showing that the majority of the yeast population maintained diploids in the 240 hour methanol induction. Finally, we compare recombinant protein productivities between a $P$. pastoris haploid IgG1 production strain and its isogenic, homozygous diploid clone. We show that diploid P. pastoris offers comparable protein productivity and $\mathrm{N}$-glycosylation profile to its haploid counterpart.

As an application of mating $P$. pastoris haploids, we used mating to evaluate the ability of two libraries, one light chain and one heavy chain to produce unique functional antibody leads. The successful development of a $P$. pastoris display mating library can streamline the $\mathrm{mAb}$ discovery, maturation, and production in the humanized glycoengineered $P$. pastoris platform, enabling simultaneous screening of high affinity and satisfactory expression antibody leads. As a proof-of-concept study, we started with an IgG1 with a known affinity for its antigen and designed a small sequence variation library focusing on heavy-chain and light-chain CDR3 regions. The library contained $>4,000$ heavy-chain variants and $>1,200$ light-chain variants. Through mating of heavy and light chain P. pastoris haploid libraries, a diploid library containing more than $10^{8}$ colonies was successfully constructed, offering a greater than $10 \times$ coverage of the theoretical diversity.

\section{Results}

\section{Construction of diploid P. Pastoris strains by mating}

To demonstrate the feasibility of using diploid $P$. pastoris strains for heterologous protein expression, we designed two expression vectors, pGLY10969 and pGLY10970 encoding the protein sequences for the light-chain and the heavy-chain of an anti-HER2 antibody, respectively. Their expressions are under the control of the AOX1 promoter and TEF transcriptional terminator (Figure 1a and 1b). To ensure the mating, two dominant selection markers are used, where plasmid pGLY10969 uses the S. cerevisiae ARR3 gene (ARS, confers resistance to arsenic) and plasmid pGLY10970 uses the Streptomyces noursei nourseothricin acetyltransferase gene (NAT, confers resistance to nourseothricin).

In order to understand the stability of diploids during methanol induction, plasmid pGLY10969 contains mCherry, a red fluorescent protein (RFP), and plasmid pGLY10970 includes yEGFP3, a green fluorescent protein (GFP), both regulated by the constitutive TEF promoter and the AOX1 transcription terminator. The plasmids also comprise the URA6 ORF as an integration locus. By linearizing at the unique SpeI restriction site within URA6 region, both vectors are integrated into the URA6 genomic locus via single crossover.

Table 1 lists the yeast strains used in this study. As shown in Figure 2, plasmids pGLY10969 and pGLY10970 were separately transformed into a parental strain to obtain two haploid strains. The diploid strains were constructed by mating these haploids followed by selection on plates containing nourseothricin and 

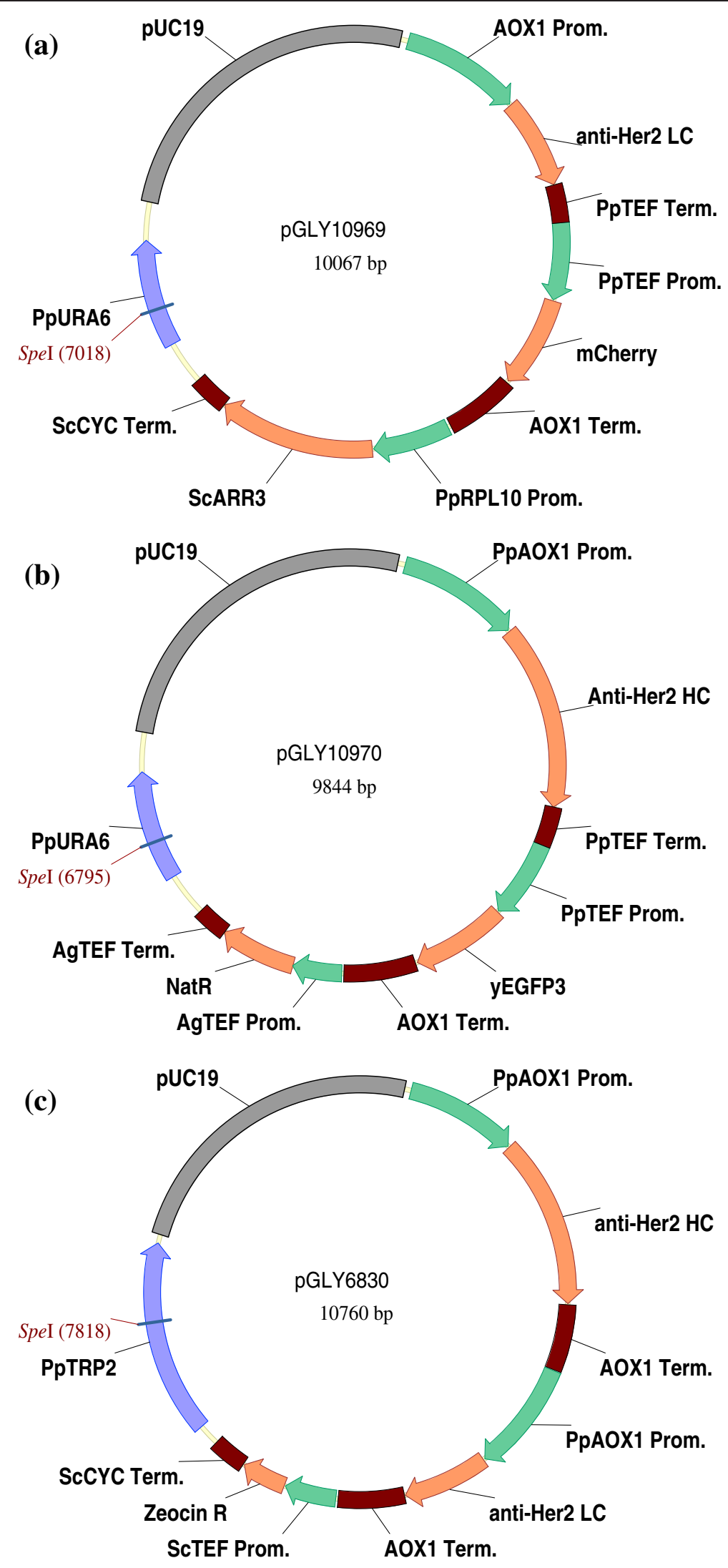

Figure 1 (See legend on next page.) 
(See figure on previous page.)

Figure 1 Vectors for anti-HER2 light-chain and heavy chain expression. (a) Plasmid pGLY10969 encodes the light chain of anti-HER2 antibody and mCherry red fluorescent protein in association with the arsenic resistance selection marker and targets the URA6 locus in P. pastoris genome (b) Plasmid pGLY10970 encodes the heavy chain of anti-HER2 antibody and yEGFP3 green fluorescent protein in association with nourseothricin resistance selection marker and targets the URA6 locus in P. pastoris genome. (c) Plasmid pGLY6830 encodes both light-chain and heavy-chain of anti-HER2 expression cassettes in association with zeocin resistance selection marker and targets to the TRP2 locus in P. pastoris genome. The Spel restriction enzyme site used to linearize each vector prior to yeast transformation is underlined.

arsenic. Since both expression cassettes were integrated into the URA6 locus, haploid progeny resulting from diploid sporulation could contain only one of the two expression cassettes. Consequently, only diploid cells were both nourseothricin and arsenic resistant $\left(\mathrm{NAT}^{+}\right.$ $/ \mathrm{ARS}^{+}$), simultaneously expressed GFP and RFP, and secreted fully-assembled anti-HER2 antibody into the media. These features facilitated the monitoring of diploid population stability by using flow cytometry and selection plate methods, and were later used in the quantitative estimation of diploid population during the protein expression process.

We used a filter-based mating protocol to determine the maximum mating efficiency in $P$. pastoris. We estimated that the maximum mating efficiency for the wild- type haploid P. pastoris strain (NRRL-Y11430) is about $10^{-2}$ (i.e. $1 \%, 1$ diploid per 100 haploid cells) after 3 days, $25^{\circ} \mathrm{C}$ mating plate incubation. We reduplicated the filter mating experiment with och $1 \Delta$ glyco-engineered strains and found that the mating efficiencies of both the och $1 \Delta$ strain (YGLY2-3) and the GS2.0 strain (YGLY8292) are around $10^{-3}$ (i.e. $0.1 \%, 1$ diploid per 1000 haploid cells). Not only did the och $1 \Delta$ strains show a 10 -fold decrease in maximum mating efficiency, but cells additionally required 5 days of mating plate incubation to reach maximum fusion (Table 2).

It should be noted that we calculated the mating efficiency based on the number of selective growth of crossed diploids using complementary markers. Because cells of the same strain could also mate, the total number of

Table 1 Yeast strains used in this study

\begin{tabular}{|c|c|c|c|c|c|}
\hline Strain & Ploidy & Parent & Plasmid & Glycan Structure & Genotype \\
\hline NRRL-Y11430 & haploid & N/A & N/A & wild-type & $\mathrm{OCH} 1$ wild-type $\mathrm{N}$-glycan $P$. pastoris \\
\hline YGLY2-3 & haploid & N/A & N/A & och $1 \Delta$ & och1- N-glycan P. pastoris \\
\hline YGLY8292 & haploid & N/A & $\mathrm{N} / \mathrm{A}$ & GS2.0 (Man5) & och1- glycoengineered GS2.0 starting strain* \\
\hline YGLY8316 & haploid & N/A & $\mathrm{N} / \mathrm{A}$ & GS5.0 (G2) & och 1- glycoengineered GS5.0 starting strain* \\
\hline YGLY27429 & haploid & NRRL-Y11430 & pGLY10969 & wild-type & URA6::AOX1p-anti-HER2-Lc, TEFp-mCherry, Ars \\
\hline YGLY27430 & haploid & NRRL-Y11430 & pGLY10970 & wild-type & URA6::AOX1 p-anti-HER2-Hc, TEFp-GFP, Nat \\
\hline \multirow[t]{2}{*}{ YGLY27431 } & \multirow{2}{*}{\multicolumn{2}{|c|}{ diploid YGLY27429/YGLY27430 }} & $\mathrm{N} / \mathrm{A}$ & wild-type & URA6::AOX1 p-anti-HER2-Lc, TEFp-mCherry, Ars \\
\hline & & & & & URA6::AOX1 p-anti-HER2-Hc, TEFp-GFP, Nat \\
\hline \multirow[t]{2}{*}{ YGLY27432 } & haploid & NRRL-Y11430 & pGLY10969 pGLY10970 & wild-type & URA6::AOX1p-anti-HER2-Lc, TEFp-mCherry, Ars \\
\hline & & & & & URA6::AOX1 p-anti-HER2-Hc, TEFp-GFP, Nat \\
\hline YGLY27433 & haploid & YGLY8292 & pGLY10969 & GS2.0 (Man5) & URA6::AOX1p-anti-HER2-Lc, TEFp-mCherry, Ars \\
\hline YGLY27434 & haploid & YGLY8292 & pGLY10970 & GS2.0 (Man5) & URA6::AOX1p-anti-HER2-Hc, TEFp-GFP, Nat \\
\hline \multirow[t]{2}{*}{ YGLY27435 } & \multirow{2}{*}{\multicolumn{2}{|c|}{ diploid YGLY27433/YGLY27434 }} & N/A & GS2.0 (Man5) & URA6::AOX1 p-anti-HER2-Lc, TEFp-mCherry, Ars \\
\hline & & & & & URA6::AOX1 p-anti-HER2-Hc, TEFp-GFP, Nat \\
\hline \multirow[t]{2}{*}{ YGLY27436 } & haploid & YGLY8292 & pGLY10969 pGLY10970 & GS2.0 (Man5) & URA6::AOX1p-anti-HER2-LC, TEFp-mCherry, Ars \\
\hline & & & & & URA6::AOX1p-anti-HER2-Hc, TEFp-GFP, Nat \\
\hline YGLY13979 & haploid & YGLY8316 & pGLY6830 & GS5.0 (G2) & TRP2::AOX1p-anti-HER2-Lc, AOX1p-anti-HER2-Hc, Zeocin \\
\hline YGLY19313 & haploid & YGLY13979 & N/A & GS5.0 (G2) & TRP2::AOX1p-anti-HER2-Lc, AOX1p-anti-HER2-Hc, Zeocin, ura5- \\
\hline YGLY19853 & haploid & YGLY19313 & pGLY24 & GS5.0 (G2) & TRP2::AOX1p-anti-HER2-Lc, AOX1p-anti-HER2-Hc, Zeocin, arg3- \\
\hline \multirow[t]{2}{*}{ YGLY19895 } & diploid & -Y19313/YGLY19853 & N/A & GS5.0 (G2) & TRP2::AOX1 p-anti-HER2-Lc, AOX1p-anti-HER2-Hc, Zeocin \\
\hline & & & & & TRP2::AOX1p-anti-HER2-Lc, AOX1p-anti-HER2-Hc, Zeocin \\
\hline
\end{tabular}


actual mating events can be up to twice the number reported here when self-mated diploids were included.

Confirmation of mated diploids was accomplished by colony PCR (cPCR) using the primer sets specific to the anti-HER2 light chain and heavy chain listed in Table 3. Figure 3 verifies that diploid strains contain genetic elements from both parental haploids. Lanes 1 and 2 of Figure $3 \mathrm{a}$ show that $\mathrm{cPCR}$ of the heavy-chain containing haploid strains (YGLY27430 and YGLY27434) produced a band using the heavy-chain specific primer set and no product was generated in light-chain containing haploid strains (YGLY27429 and YGLY27433). Likewise, lanes 3 and 4 of Figure $3 \mathrm{~b}$ show that $\mathrm{CPCR}$ of the light-chain containing haploids (YGLY27429 and YGLY27433) produced a band using the light-chain specific primer set and no product was seen in heavy-chain only haploids.

Table 2 Mating efficiency of $\mathrm{OCH} 1$ wild-type and glycoengineered $\boldsymbol{P}$. pastoris strains

\begin{tabular}{|c|c|c|c|c|}
\hline Parental Haploid Strain & Glycan Structure & Mating Condition & Diploid Selection Markers & Estimated Maximum Mating Efficiency \\
\hline NRRL-Y11430 & OCH1 wild-type & 3 days, $25^{\circ} \mathrm{C}$ & ARS, NAT & $10^{-2}$ \\
\hline NRRL-Y11430 & OCH1 wild-type & 3 days, $25^{\circ} \mathrm{C}$ & Arg1, His1 & $10^{-2}$ \\
\hline NRRL-Y11430 & OCH1 wild-type & 3 days, $25^{\circ} \mathrm{C}$ & Arg3, His1 & $10^{-2}$ \\
\hline NRRL-Y11430 & OCH1 wild-type & 3 days, $25^{\circ} \mathrm{C}$ & Arg3, His4 & $10^{-2}$ \\
\hline YGLY2-3 & och1 $\Delta$ & 5 days, $25^{\circ} \mathrm{C}$ & ARS, NAT & $10^{-3}$ \\
\hline YGLY2-3 & och $1 \Delta$ & 5 days, $25^{\circ} \mathrm{C}$ & Zeocin, ARS & $10^{-3}$ \\
\hline YGLY2-3 & och1 $\Delta$ & 5 days, $25^{\circ} \mathrm{C}$ & Arg3, His1 & $10^{-3}$ \\
\hline YGLY8292 & GS2.0 (Man5) & 5 days, $25^{\circ} \mathrm{C}$ & Zeocin, ARS & $10^{-3}$ \\
\hline YGLY8292 & GS2.0 (Man5) & 5 days, $25^{\circ} \mathrm{C}$ & Zeocin, NAT & $10^{-3}$ \\
\hline YGLY8292 & GS2.0 (Man5) & 5 days, $25^{\circ} \mathrm{C}$ & ARS, NAT & $10^{-3}$ \\
\hline YGLY8292 & GS2.0 (Man5) & 5 days, $25^{\circ} \mathrm{C}$ & Arg3, His1 & $10^{-3}$ \\
\hline YGLY8316 & GS5.0 (G2) & 5 days, $25^{\circ} \mathrm{C}$ & Zeocin, ARS & $2.5 \times 10^{-4}$ \\
\hline YGLY8316 & GS5.0 (G2) & 5 days, $25^{\circ} \mathrm{C}$ & Zeocin, NAT & $2.5 \times 10^{-4}$ \\
\hline YGLY8316 & GS5.0 (G2) & 5 days, $25^{\circ} \mathrm{C}$ & ARS, NAT & $2.5 \times 10^{-4}$ \\
\hline YGLY8316 & GS5.0 (G2) & 5 days, $25^{\circ} \mathrm{C}$ & Arg3, Ura5 & $10^{-5 *}$ \\
\hline
\end{tabular}

*ura5- strain has a slow growth phenotype. 
Table 3 Primers used to confirm the existence of anti-HER2 light and heavy chains in diploid genome

\begin{tabular}{llll}
\hline Reaction & Primer Name & \multicolumn{1}{c}{ Primer Sequence (5' to 3') } & Primer Description \\
\hline PCR-HC & MT3 & GGTTCCAATTGACAAGCTTTTGATTTAACG & AOX1p_Forword \\
\cline { 2 - 4 } & MT126 & GTCCTCGTGAGAAACGTC & Anti_HER2_Hc_Reverse \\
\hline PCR-LC & MT3 & GGTTCCAATTGACAAGCTTTTGATTTAACG & AOX1p_Forword \\
\cline { 2 - 4 } & MT132 & CTCTCTTGGGTAGAAGTTGTTCAACAA & Anti_HER2_LC_Reverse \\
\hline
\end{tabular}

Lanes 5-7 and 8-10 in Figure 3a and 3b indicate diploid colonies obtained from the mating of YGLY27430/ YGLY27429 and YGLY27434/YGLY27433, where the presence of anti-HER2 heavy-chain and light-chain expression cassettes in the genome was confirmed by cPCR. Several hundred colonies from each mating reaction were analyzed by $\mathrm{CPCR}$, revealing that more than
$98 \%$ of colonies growing on selection media were diploid. Figure 3c displays representative microscopy fluorescence observations of wild-type haploid strains YGLY27430, YGLY27429 and their crossed diploid strain YGLY27431. Similar microscopy fluorescence was observed in the glycoengineered strain background (data not shown). (a)

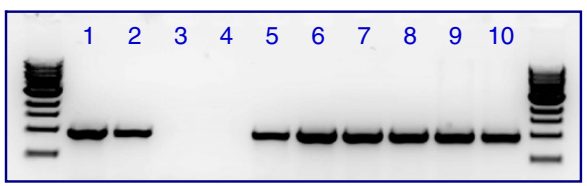

Heavy-chain specific cPCR (b)

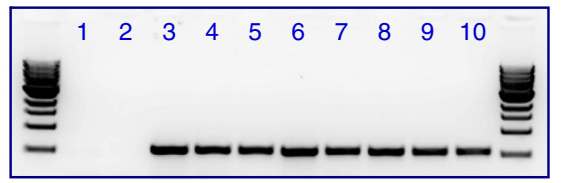

Light-chain specific cPCR

\begin{tabular}{|c|c|l|}
\hline 1 & YGLY27430 & Haploid strain (OCH1 wild type) containing anti-Her2 heavy chain only. \\
\hline 2 & YGLY27434 & Haploid strain (GS2.0) containing anti-Her2 heavy chain only. \\
\hline 3 & YGLY27429 & Haploid strain (OCH1 wild type) containing anti-Her2 light chain only. \\
\hline 4 & YGLY27433 & Haploid strain (GS2.0) containing anti-Her2 light chain only. \\
\hline $5-7$ & $\begin{array}{l}\text { Diploid strains obtained from the mating of YGLY24730 and YGLY24729. Diploid strains contain } \\
\text { both anti-Her2 heavy chain and light chain in the genome. }\end{array}$ \\
\hline $8-10$ & $\begin{array}{l}\text { Diploid strains obtained from the mating of YGLY24733 and YGLY24734. Diploid strains contain } \\
\text { both anti-Her2 heavy chain + light chain in the genome. }\end{array}$ \\
\hline
\end{tabular}

(c)

YGLY27430

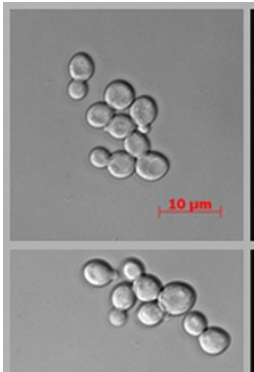

YGLY27429

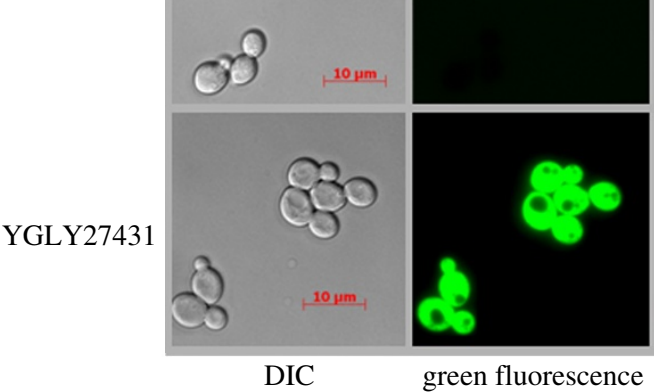

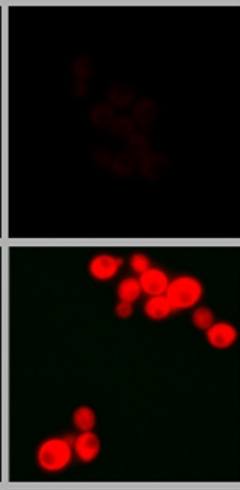

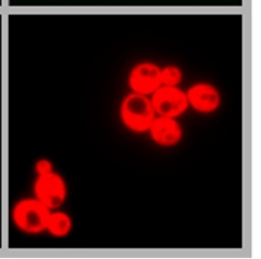

red fluorescence

Figure 3 PCR and microscopy confirmation of diploid polyploidy. For $\mathbf{a}$, and $\mathbf{b}$, the primer sets listed in Table 3 were used to confirm the existence of anti-HER2 light and heavy chain expression cassettes in the diploid chromosome. 
We repeated the mating experiments using different combinations of the dominant markers Zeocin, NAT, and ARS as well as the auxotrophic markers ARG1, ARG3, HIS1, HIS4, and URA5. In all tested mating circumstances, the mating efficiency in all och1 $1 \Delta$ strains was found to be around $0.1 \%$ (Table 2), irrespective of the glycoengineered strains (GS2.0, and GS5.0). In wildtype $P$. pastoris, $\mathrm{N}$-glycan structures consist mostly of $\operatorname{Man}_{15-30}$ with varying degrees of charged glycans. By comparison, $\mathrm{N}$-glycans of och $1 \Delta$ mutant strain are predominantly $\mathrm{Man}_{8-12}$, representing a noticeable shift to smaller glycans due to the lack of the outer chain [7]. Our results suggest that the knockout of och1 decreases mating efficiency by 10 fold, likely because of decreased levels of mannose proteins in the och $1 \Delta$ mutants, and that further glycoengineering has a negligible impact on mating fitness.

\section{Recombinant anti-HER2 production and diploid strain stability in methanol}

To understand heterologous protein production in diploid $P$. pastoris strains and diploid stability in methanol media, diploid yeasts YGLY27431 (wild-type) and YGLY27435 (och1, GS2.0) were induced in 2\% BMMY methanol media for 72 hours in shake flasks for anti-HER2 production. Diploid strain stability was quantitatively determined by analyzing the percentage of diploid cells in the total cell population at $12 \mathrm{hr}$ time intervals. The red curve in Figure $4 \mathrm{a}$ depicts the diploid population percentage of YGLY27431 over the 72 hour methanol induction period. The diploid population was maintained at around 100\% throughout the entire methanol induction time. No obvious sporulation events were observed. Similarly, a stable diploid population was observed in the glycoengineered strain YGLY27435 (Figure 4a, blue curve).
We applied the same plate-based stability assay to examine diploid strain stability in nitrogen-deprived sporulation media. Figure $4 \mathrm{~b}$ shows the diploid population in strains YGLY27431 and YGLY27435 in a nitrogen-deprived environment. A significant number of sporulation events were observed in the wild-type diploid strain YGLY27431 after $48 \mathrm{hrs}$ in sporulation media (Figure 4b, red curve). After $72 \mathrm{~h}$ incubation, only about $40 \%$ of the cell population retained a diploid phenotype. Meanwhile, the glycoengineered diploid strain YGLY27435 (blue curve) appeared to sporulate at much lower frequency. This observation was consistent with a previous report in a $S$. cerevisiae och $1 \Delta /$ och $1 \Delta$ diploid strain where sporulation was reported to occur at a reduced efficiency [23].

It is worth mentioning that because $P$. pastoris asci contain up to 4 haploid ascospores, 1 diploid sporulation event might therefore generate up to 4 survival colonies on the non-selection plate if the spores are well separated. As a result, our plate-based stability curves reflect a relative but sensitive method to monitor diploid stability rather than absolute sporulation frequencies. In the case of Figure $4 \mathrm{~b}$ data, $40 \%$ of the total diploid population could be caused by merely $25 \%$ of diploid cells undergoing sporulation, assuming that all $P$. pastoris spores were disjointed.

Diploid stability was also analyzed using flow cytometry. Figure $5 \mathrm{a}$ and $5 \mathrm{~b}$ depict the green and red fluorescence profiles of the haploid yeast strains YGLY27430 (GFP-expressing only) and YGLY27429 (RFP-expressing only), respectively. Both haploids formed a distinct and highly fluorescent population distribution in their corresponding color channels. Figure $5 \mathrm{c}$ displays the fluorescence profiles of the diploid strain YGLY27431 and Figure 5d shows the fluorescence profiles of the diploid strain YGLY27431 under methanol induction over a (a)

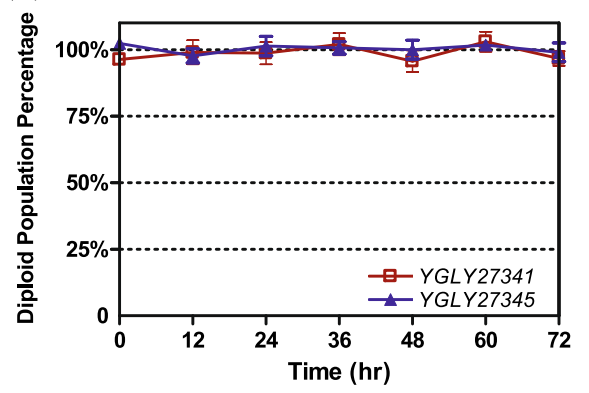

(b)

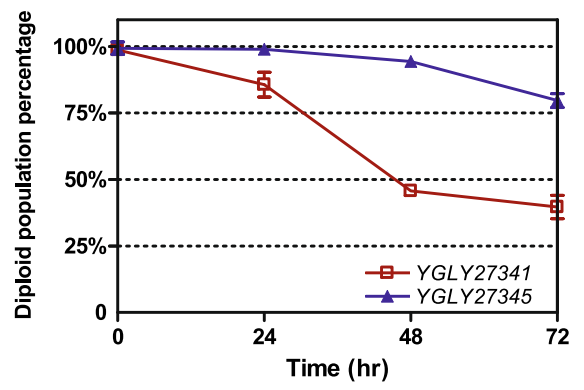

Figure 4 Diploid strain stability analysis. (a) Diploid strain stability showing total diploid population percentage in shake flasks followed by a methanol induction phase over 72 hour induction time course. (b) Time-dependent diploid stability in nitrogen-deprived sporulation media. For $\mathbf{a}$, and $\mathbf{b}$, percentage of diploid population was determined by the number of colonies growing on a diploid selection plate in comparison with the number of colonies growing in a non-selective plate. Symbols represent the average measurement values from triplicate experiments. As controls, parental haploid strains carrying either ARS or NAT selection marker did not form any colonies on selection plates containing both arsenic and nourseothricin (data not shown). 
(a) YGLY27430, GFP-expressing only, haploid

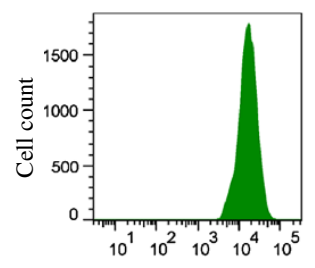

green fluorescence (a.u.)
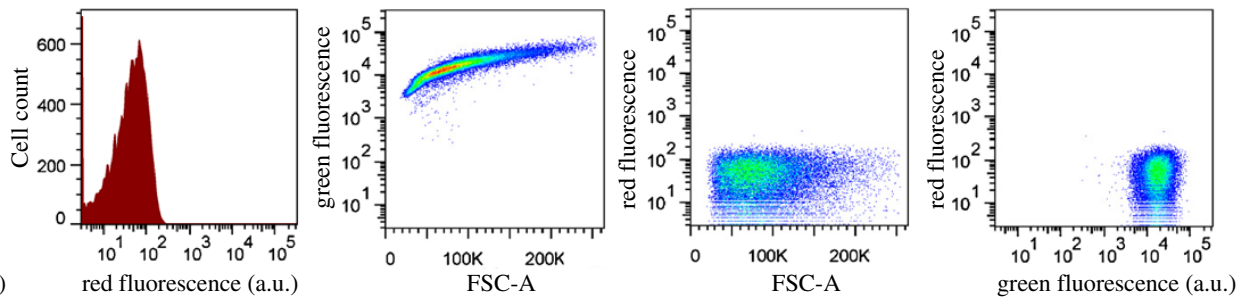

(b) YGLY27429, RFP-expressing only, haploid
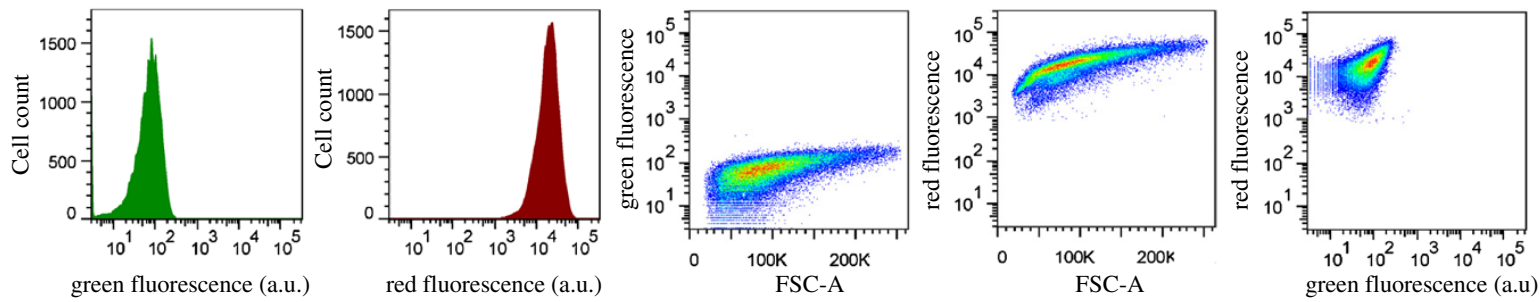

(c) YGLY27431, GFP and RFP-expressing, diploid
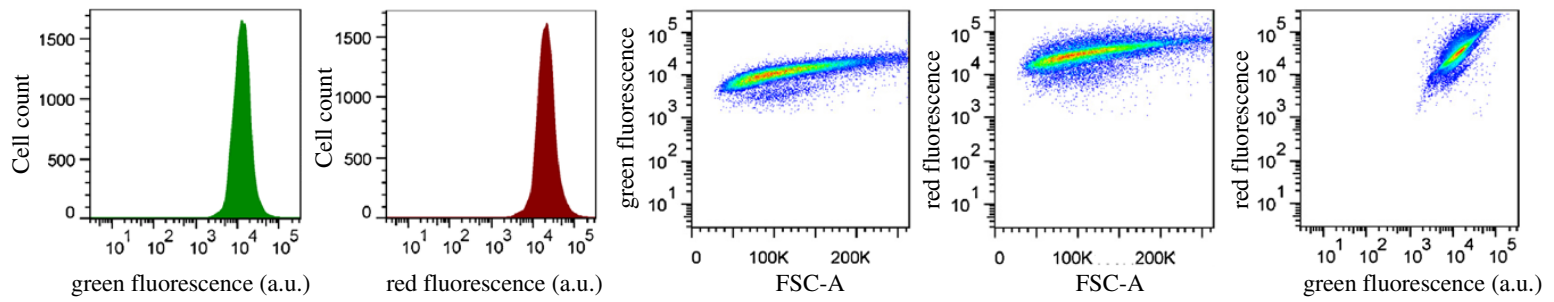

(d) YGLY27431, GFP and RFP-expressing, in BMMY media
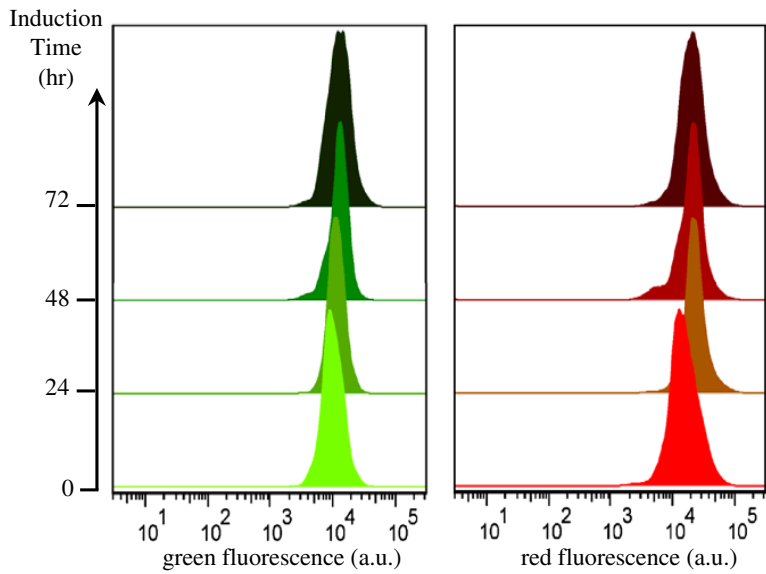

(e) YGLY27431, 72 hours in sporulation media
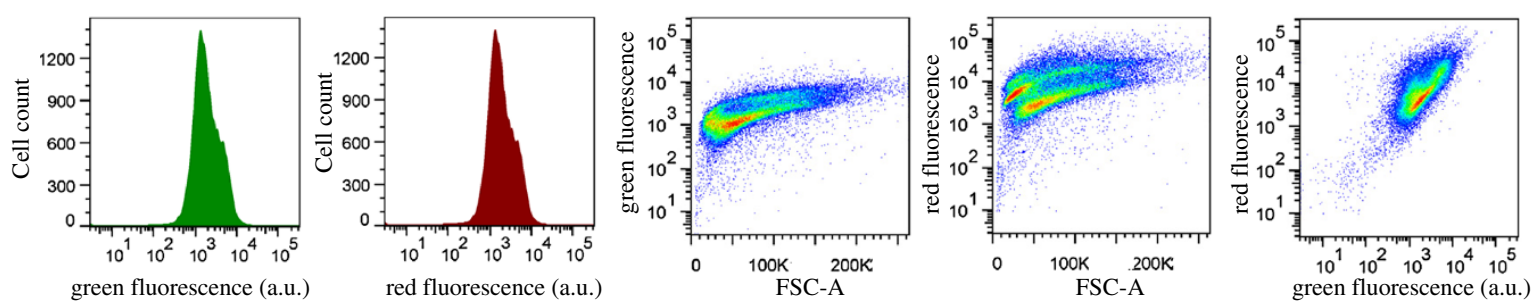

Figure $\mathbf{5}$ (See legend on next page.) 
(See figure on previous page.)

Figure $\mathbf{5}$ Evaluation of diploid strain stability using flow cytometry analysis. (a) Green and red fluorescence intensities of parental haploid yeast strain YGLY27430 (expressing only GFP). (b) Green and red fluorescence intensities of parental haploid yeast strain YGLY27429 (expressing only RFP). (c) Green and red fluorescence intensities of diploid yeast strain YGLY27431 (expressing both GFP and RFP). (d) Time course of green and red fluorescence intensities of diploid yeast strain YGLY27431 in shake-flask, methanol induction media. Fluorescence intensities were measured at 24-hour time intervals. (e) Fluorescence intensities of diploid yeast strain YGLY27431 after 72 hours cultivation in nitrogen-deprived sporulation media. For $\mathbf{a}, \mathbf{b}, \mathbf{c}, \mathbf{d}$ and $\mathbf{e}$, all yeast strains contained OCH1 wild-type N-glycan. Similar flow cytometry profiles were also observed in several different GS2.0 strain lineages YGLY27433, YGLY27434, and YGLY27435 (data not shown).

time scale of $0-72$ hours. Strain YGLY27431 retained strong GFP and RFP co-expression profiles throughout the 72 hour methanol induction period, suggesting that the diploid strains were stable under the conditions tested.

As a control experiment, when incubated for $72 \mathrm{hrs}$ in nitrogen-deprived sporulation media, diploid cells formed two distinctive population distributions in both green and red fluorescence channels (Figure 5e). The high green fluorescence cell population corresponded to the vegetative diploid population, and the lower green fluorescence cell population could be explained by protein degradation during the sporulation process or lysis of the anucleate mother cell. Both green and red fluorescence profiles of the flow cytometry experiment provided reliable, real-time monitoring of diploid strain stability. Similar flow cytometry results were observed in the glycoengineered diploid strain YGLY27435 (data not shown).

\section{Bio-analytical characterization of anti-HER2 produced in diploid $P$. Pastoris strains}

Figure 6a shows the reducing and non-reducing SDSPAGE for anti-HER2 material generated by diploid $P$. pastoris strains and their comparison with anti-HER2 material generated by haploid $P$. pastoris strains and commercial trastuzumab. Anti-HER2 produced by diploid $P$. pastoris strains was well assembled and included the expected tetramer of two heavy and two light chains. An intact protein mass analysis was confirmed by liquid chromatography-mass spectrometry (LC-MS) after release of the N-glycan (Figure 6b). HER2 target binding of $P$. pastoris produced anti-HER2 was verified by surface plasmon resonance (Table 4). Similar kinetic binding constants were found for anti-HER2 produced in both diploid and haploid P. pastoris strains.

\section{Bioreactor cultivations of $P$. Pastoris diploids}

We examined fermentability of diploid $P$. pastoris strains YGLY27431 (wild-type) and YGLY27435 (och1, GS2.0) using a simple fed-batch, carbon-limited 3 Liter fermentation platform. As shown in Figure $7 \mathrm{a}$ and $7 \mathrm{~b}$, both strains displayed an increase in antibody titer and WCW over a 10 day methanol induction time course. The anti-HER2 titers of diploid strains YGLY27431 and
YGLY27435 at harvest were $227 \mathrm{mg} / \mathrm{L}$ and $148 \mathrm{mg} / \mathrm{L}$, respectively under the suboptimal, constant feed rate fermentation conditions. The non-reducing SDS-PAGE in Figure $7 c$ and $7 d$ shows the high quality of fully assembled anti-HER2 material produced.

We analyzed diploid stability using both a plate-based stability assay and flow cytometry (Figure 8 a-c), and we observed a steady decrease in the diploid population (i.e. increasing sporulation) over time. After 10 days of fermentation, the percentage of diploids in the populations for YGLY27431 and YGLY27435 were 50\% and 70\%, respectively.

FACS analysis suggested that vegetative growing GFP or RFP expressing haploid populations in culture media were minimal. The sporulated diploids mostly existed in dormant spore states. Moreover, our previous experience showed that Protein A is able to capture heavy chain monomer. In Figures $7 \mathrm{a}$ and $7 \mathrm{~b}$, there is no obvious heavy chain monomer band after protein A purification, inferring that the haploids population is not significant.

We used cPCR to corroborate the existence of vegetative diploid and sporulated populations during fermentation. Figure $8 \mathrm{~d}$ shows the $\mathrm{CPCR}$ results from 10 randomly picked colonies of YGLY27431 fermentation samples (10 days) growing on ARS/NAT selection plates. All colonies produced the PCR bands of anti-HER2 heavy and light chains, confirming their diploid genotype. Confirmation of ascospore formation in fermentation samples was done using diethyl ether extraction followed by cPCR. The cPCR result of 18 randomly picked colonies of diethyl ether treated YGLY27431 fermentation samples revealed that colonies contained either the heavy chain or light chain sequence in its genome but not both, confirming their haploidy. Similar cPCR results were observed in YGLY27435 fermentation samples (data not shown).

\section{Comparison of recombinant protein production between haploids and isogenic diploids}

The above results show that both wild-type and glycoengineered $P$. pastoris diploid strains are able to provide efficient and reliable anti-HER2 protein production in an established carbon-limited fermentation process. Our next aim is to perform a head-to-head assessment of recombinant protein production in a haploid $P$. pastoris 
(a)

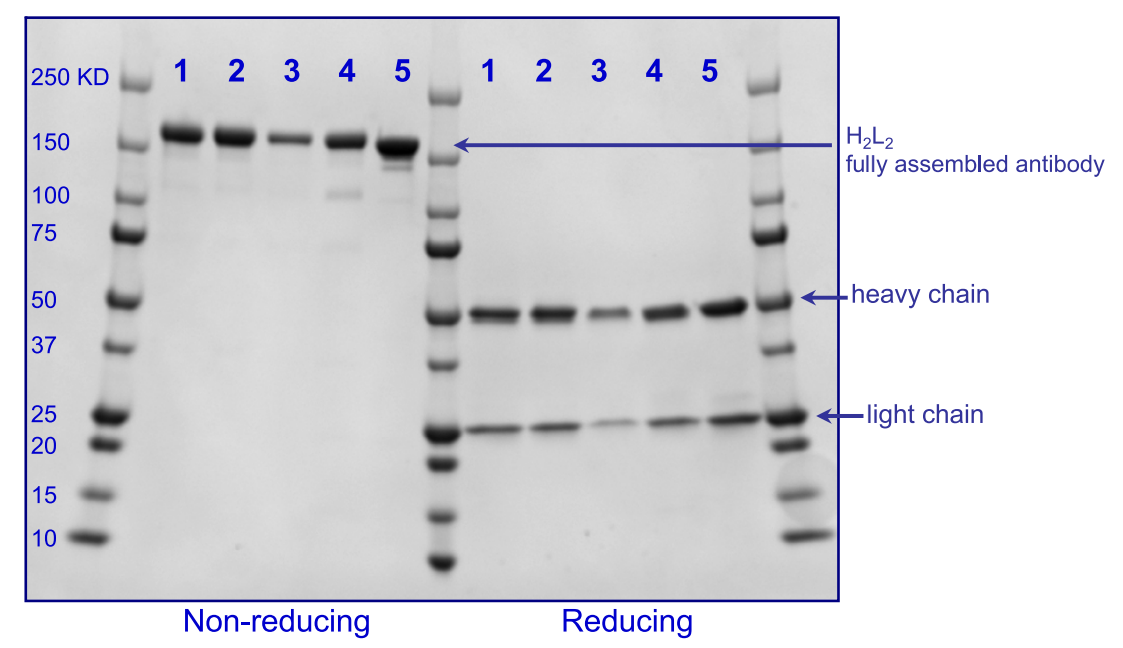

(b)
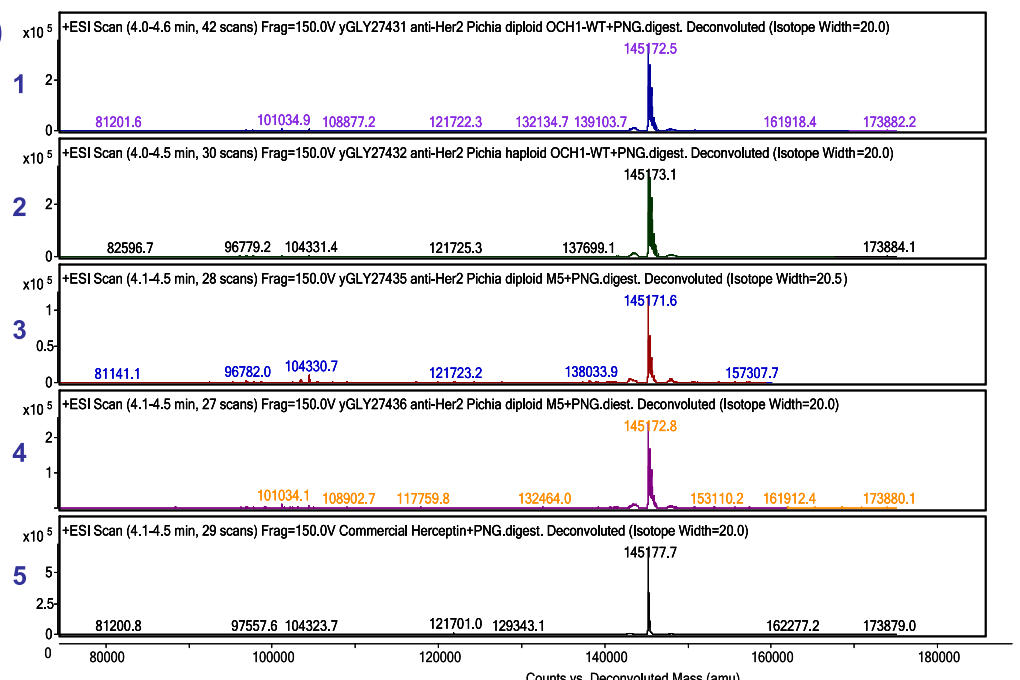

\begin{tabular}{|l|l|}
\hline 1 & anti-Her2 produced in yGLY27431 (diploid, OCH1 wild type) \\
\hline 2 & anti-Her2 produced in yGLY27432 (haploid, OCH1 wild type) \\
\hline 3 & anti-Her2 produced in yGLY27435 (diploid, GS2.0) \\
\hline 4 & anti-Her2 produced in yGLY27436 (haploid, GS2.0) \\
\hline 5 & Trastuzumab, anti-Her2 produced in CHO cell \\
\hline
\end{tabular}

Figure 6 Characterization of diploid P. pastoris-derived antibody. (a) SDS-PAGE showing the quality of an anti-HER2 antibody produced in diploid P. pastoris strains in comparison with anti-HER2 material produced in haploid P. pastoris strains and their comparison with trastuzumab produced from CHO cells. (b) LC-MS mass spectrometry of anti-HER2 antibodies after release of N-glycan. For $\mathbf{a}$, and $\mathbf{b}$, anti-HER2 material produced in yeast strains was purified by affinity capture using protein A beads.

Table 4 Kinetic binding constants of $P$. pastoris produced anti-HER2

\begin{tabular}{|c|c|c|c|c|c|}
\hline Samples & Description & $k_{\mathrm{a}}\left(1 / \mathrm{M}^{*} \mathrm{~s}\right)$ & $k_{d}(1 / s)$ & $K_{D}(\mathrm{nM})$ & Ave. $K_{D}(\mathrm{nM})$ \\
\hline YGLY27431 & $\begin{array}{l}\text { OCH1 wild-type, } \\
\text { diploid }\end{array}$ & $4.0 \mathrm{E}+4$ & $1.9 \mathrm{E}-4$ & 4.7 & 4.63 \\
\hline YGLY27432 & $\begin{array}{l}\text { OCH1 wild-type, } \\
\text { haploid }\end{array}$ & $4.4 \mathrm{E}+4$ & $1.8 \mathrm{E}-4$ & 4.2 & \\
\hline YGLY27435 & GS2.0, diploid & $4.1 \mathrm{E}+4$ & $2.2 \mathrm{E}-4$ & 5.3 & \\
\hline YGLY27436 & GS2.0, haploid & $3.9 \mathrm{E}+4$ & 1.7E-4 & 4.3 & \\
\hline
\end{tabular}

production strain versus its isogenic homozygous diploid clone using $\mathrm{N}$-glycan quality and protein titer as readouts. The haploid strain YGLY13979 was constructed by transforming plasmid pGLY6830 (Figure 1c) encoding both the light chain and heavy chain of anti-HER2 regulated by the AOX1 promoter into strain YGLY8316 [24]. Glycoproteins expressed in this strain were decorated with biantennary complex N-linked glycans. 
(a)

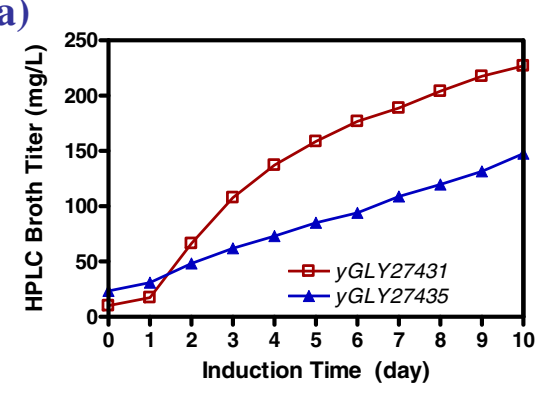

(c)

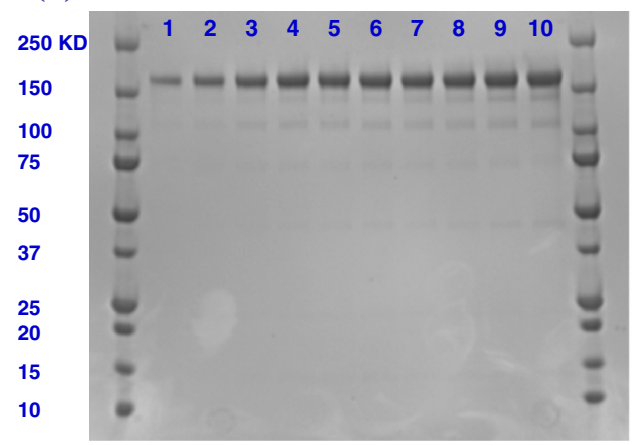

(b)

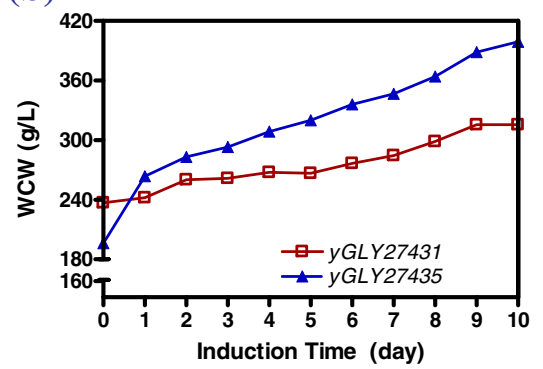

(d)

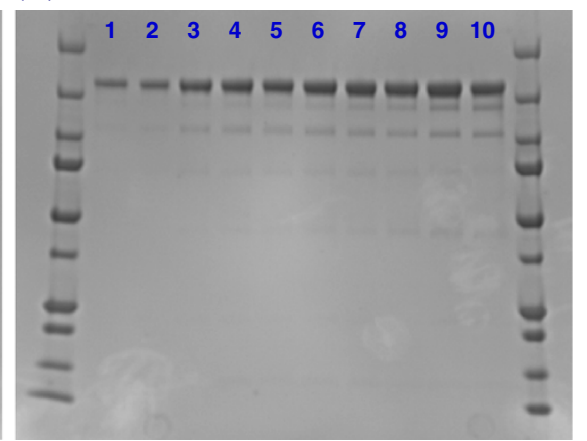

Figure 7 Time course of protein productivity, biomass, and SDS-PAGE of diploid yeast strains YGLY27431 and YGLY27435 under fedbatch high-cell-density fermentation. (a) Anti-HER2 productivity showing HPLC broth titer as a function of time. (b) Biomass showing WCW as a function of time. (c) Non-reducing SDS-PAGE of Protein-A captured YGLY27431 fermentation product. (d) Non-reducing SDS-PAGE of Protein-A captured YGLY27435 fermentation product.

We constructed YGLY19895, the isogenic homozygous diploid of YGLY13979, using URA5 and ARG3 auxotrophic markers as described in Methods. Table 5 lists the comparison of protein titer and glycan quality produced in strains YGLY13979 and YGLY19895 in a $1 \mathrm{~L}$ scale fermentor $(\mathrm{n}=3)$. The diploid strain YGLY19895 had comparable broth titers to its haploid $P$. pastoris production counterpart ( $94 \%$ titer, within normal range deviation, $\mathrm{n}=3$ ). Moreover, anti-HER2 purified from the strains showed a very similar N-linked glycosylation profile (Table 5). Based on these observations, we suggest that diploid P. pastoris has the potential to produce proteins with high $\mathrm{N}$-glycan quality.

\section{Generation of a yeast antibody display library by mating}

The construction of a yeast antibody display library by mating is dependent on the successful selection of appropriate strains and vectors. To facilitate large-scale diploid selection and cultivation of mated diploid cells, we chose the auxotrophic markers HIS1 and ARG1 for the selection of heavy and light chain vectors, respectively. As a proof-of-concept experiment, the host strain used was a his1 $\Delta$ arg1s double auxotrophic wild-type strain. In this experiment, diploids were conveniently selected by growth in minimal liquid media without amino acid supplement. Compared with the strain selection using dominant drug markers, the use of auxotrophic makers eliminates the possibility of revertants that might arise through drug resistance.

We started with rationally designed heavy and light chain CDR3 variant libraries of an antibody with a known affinity for its antigen. The designed libraries contained $>4,000$ heavy-chain variants and $>1,200$ lightchain variants, where $S$. cerevisiae SED1 (GPI-cell wall glycoprotein) was used as a cell surface display anchor (Shaheen et al., manuscript in preparation). Through mating of heavy and light chain P. pastoris haploid libraries, a diploid library containing more than $10^{8}$ colonies was successfully constructed and covered more than 10 times theoretical diversity.

We sequenced several hundred colonies, and all clones exhibited non-identical CDR3 sequences, supporting the diversity of the designed library (data not shown). In this proof-of-concept mating experiment conducted in wildtype $P$. pastoris, we estimated the mating efficiency to be around $0.25 \%$. We successfully utilized this novel P. pastoris display system to identify a new antibody lead with improved biochemical characteristics and binding affinity using fluorescence activated cell sorting (manuscript in preparation). Our future plans include scaling up the current mating protocol to achieve a library with a diversity of $10^{10}$. 


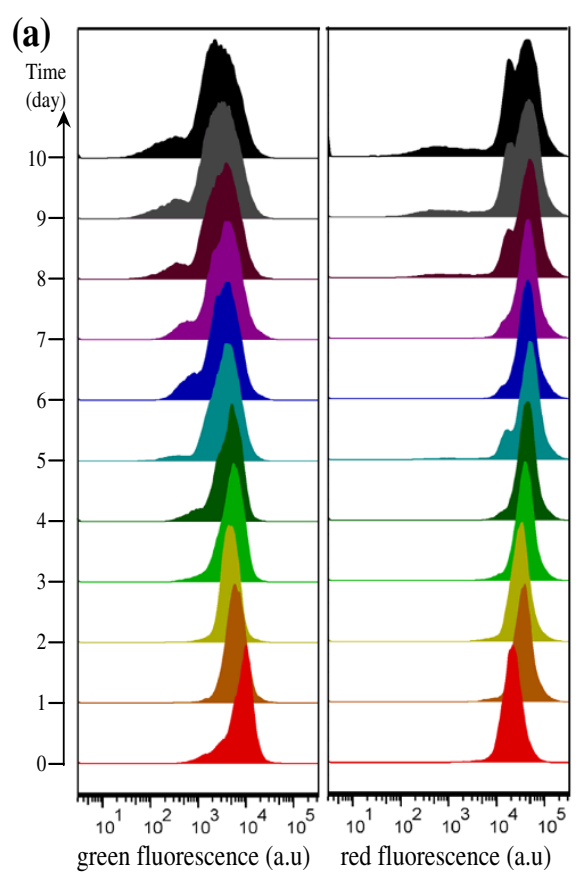

(c)

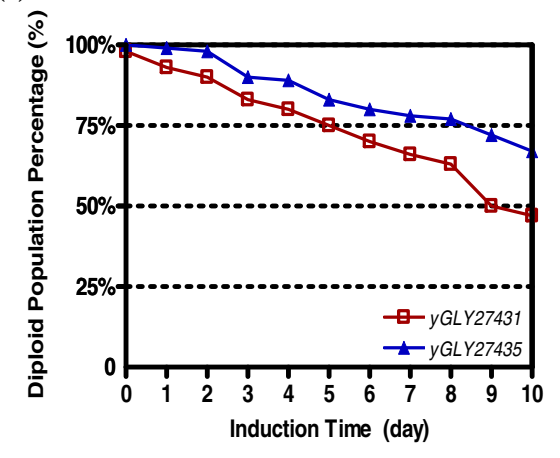

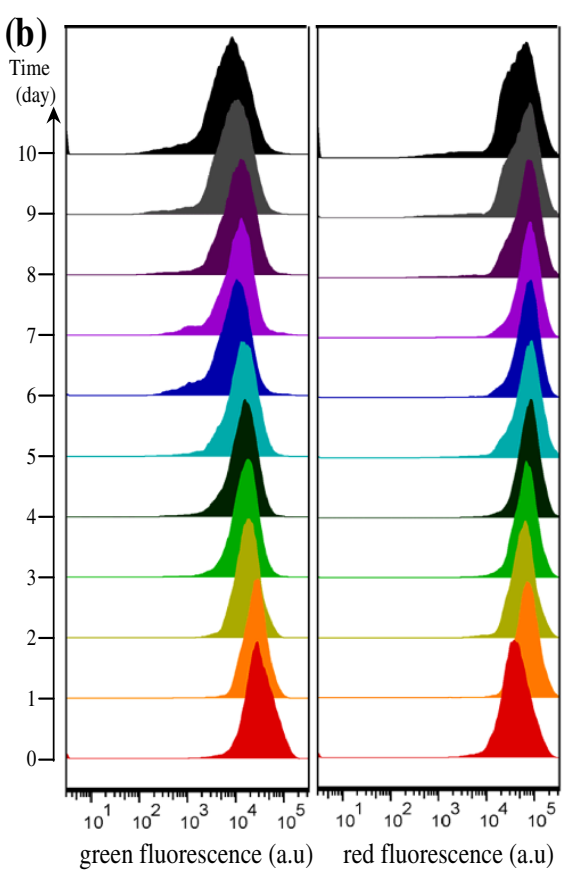

(d)
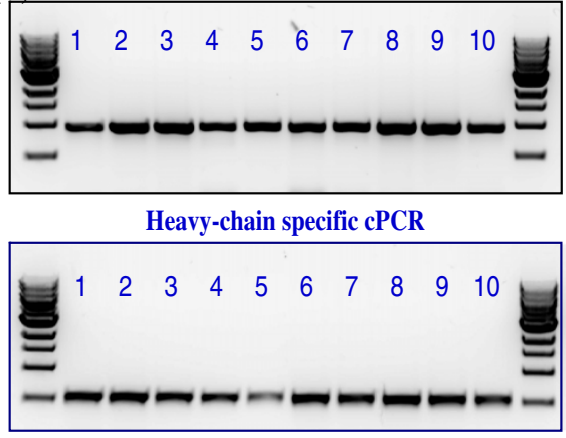

Light-chain specific cPCR

(e)
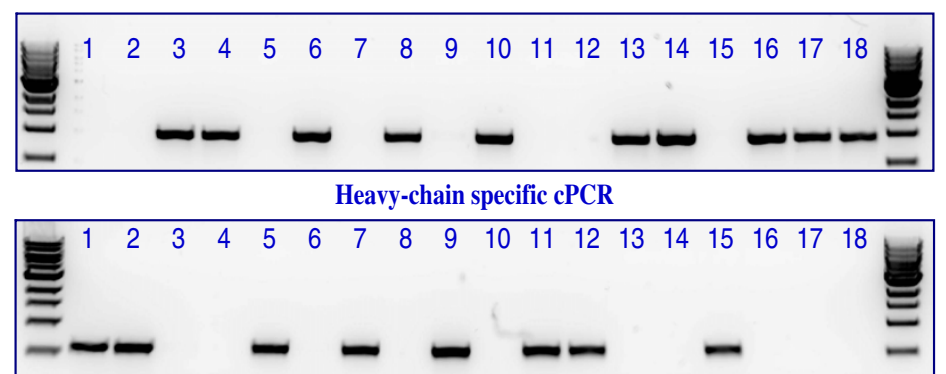

Light-chain specific cPCR

Figure 8 Diploid strain stability in high-productivity fed-batch fermentation. (a) Time course green and red fluorescence intensities of YGLY27431 showing OCH1 wild-type P. pastoris diploid strain stability over 10 days of induction. (b) Time course green and red fluorescence intensities of YGLY27435 showing glycoengineered -P. pastoris diploid strain stability over 10 days of induction. (c) Time-dependent diploid strain stability analyzed using a selection plates assay. (d) PCR confirmation of diploid genome. (e) PCR confirmation of sporulated haploid genome. For $\mathbf{a}$, and $\mathbf{b}$, fluorescence intensities were measured at 24-hour time interval using flow cytometry. For $\mathbf{c}$, percentage of diploid population was determined by the number of colonies growing in diploid selection plate in comparison with the number of colonies growing in non-selective plates. For $\mathbf{d}$, and $\mathbf{e}$, the primer sets listed in Table 3 were used to confirm the existence of anti-HER2 light and heavy chain expression cassettes in yeast chromosome. 
Table 5 Fermentation profiles of haploid yeast strain YGLY13979 in comparison with its homozygous diploid strain YGLY19895

\begin{tabular}{|c|c|c|c|c|c|c|c|}
\hline Strain & Ploidy & \multicolumn{2}{|c|}{ Supernatant HPLC Titer (mg/L) } & \multicolumn{2}{|c|}{ Broth Titer (mg/L) } & WCW (g/L) & Induction Time (hr) \\
\hline YGLY13979 & Haploid & \multicolumn{2}{|c|}{1048} & \multicolumn{2}{|c|}{780} & 255 & 96 \\
\hline YGLY19895 & Diploid & \multicolumn{2}{|c|}{920} & \multicolumn{2}{|c|}{730} & 206 & 96 \\
\hline Strain & Ploidy & Man5\% & G0\% & G1\% & $\mathrm{G} 2 \%$ & Hybrid \% & Complex \% \\
\hline YGLY13979 & Haploid & 13.3 & 60.1 & 16.8 & 3.8 & 6.0 & 80.7 \\
\hline YGLY19895 & Diploid & 15.6 & 59.1 & 15.1 & 2.5 & 7.7 & 76.7 \\
\hline
\end{tabular}

*Data represents the average measurement values from triplicate fermentation runs.

Man5: $\mathrm{Man}_{5} \mathrm{GlCNaC}_{2}$;

G0: GlcNAc $2 \mathrm{Man}_{3} \mathrm{GlcNAC}_{2}$;

G1: $\mathrm{Gal}_{1} \mathrm{GlCNAC}_{2} \mathrm{Man}_{3} \mathrm{GICNAC}_{2}$

G2: $\mathrm{Gal}_{2} \mathrm{GlCNAC}_{2} \mathrm{Man}_{3} \mathrm{GlCNAC}_{2}$;

Hybrid: GlcNAc $\operatorname{Man}_{5} \mathrm{GlcNAc}_{2}+\mathrm{Gal}_{1} \mathrm{Gl}_{\mathrm{cNAc}} \mathrm{Man}_{5} \mathrm{GlcNAc}_{2}$.

Complex: G0 + G1 + G2

\section{Discussion}

In a previous effort to humanize the protein glycosylation pathway in the yeast $P$. pastoris, we developed a systematic fusion library approach to select for the proper combination of targeting signal and catalytic domains. By sequentially screening several combinatorial genetic libraries to properly localize active eukaryotic mannosidases and glycosyltransferases, we were able to engineer the yeast glycosylation pathway to produce $\mathrm{N}$-glycans with human-like glycan structures [7-13]. The genetic manipulations required for the construction of such strains were laborious and time-consuming.

Many species of yeasts, including $P$. pastoris, are mating competent. Mating enables two distinct haploid strains to fuse and generate a diploid strain possessing genetic elements from both parental haploids. Mating diploid yeast strains therefore potentially provides a convenient and faster route for strain construction and consolidation. Conventional experience that diploid $P$. pastoris strains are unstable suggests that after mating, immediate sporulation followed by screening stable haploid strains carrying desirable genetic constructs is imperative. Since the haploid $P$. pastoris genome contains only 4 chromosomes, gene integration loci are commonly linked to some degree and are presumably not well-segregated during sporulation. Strain construction using mating hence requires carefully chosen integration loci and the number of genes of interest can be limited by available selection markers.

By using protein titer and $\mathrm{N}$-linked glycosylation profiles as quantitative readouts, we demonstrate that diploid $P$. pastoris strains offer comparable protein productivity and $\mathrm{N}$-glycosylation profile to that of a haploid strain expressing the same antibody. Our comparison is based on isogenic homozygous diploid strains. Through careful selection of desired characteristics for mating, we consider it a possibility to construct heterozygous diploid $P$. pastoris strains possessing superior productivity and better stress tolerance than parental haploids. Polyploidy yeast strains may further be constructed through spheroplast fusion. This work lays a foundation for using mating for complex $P$. pastoris strain consolidation and direct screening of mated diploids for large-scale protein production. This method will be especially suitable for the systematic screening of combinatorial genetic libraries, and the number of genes of interest will not be limited by accessible selection markers.

Improved diploid bioreactor stability can be achieved through process and media optimization. In our experiments, both shake flask cultivation and fed batch fermentation were done using the same complex nutrient rich media. There were two major differences between shake flask and fermentation conditions: cell population density and media replenishment. In a shake flask, the start of induction cell population density was much lower than fed batch fermentation. This was indicated by a measured OD of 1-5 in shake flask versus $150-200$ in fed batch fermentation. Additionally, culture media was replaced at start of induction in shake flask cultivation; while same media was carried over from growth phase into induction in fed batch fermentation. Due to both above stated reasons, the nutrient levels in fed batch fermentation would be lower than shake flask cultivation.

Based on available evidence, the authors believe that the addition of supplemental $\mathrm{N}$-source can improve the performance of diploids in fed batch. Other fermentation modes such as perfusion and continuous culture may help in improving diploid stability. Alternatively, genetic engineering approach can be applied to obtain stable diploid $P$. pastoris cell lines. For example, the knockout of IME1, a key transcriptional regulator of early meioticspecific genes, should abolish sporulation and stabilize diploid cell lines $[25,26]$. Considering that sporulation regulator genes are usually repressed under normal growth condition, we speculate that mutant ime1s, or other sporulation negative genes will have minimal effects on the AOX1 promoter activity or mating. 
Yeast display of antibody mating libraries provides a practical and productive means for selecting higher affinity and well expressing antibodies using fluorescence activated cell sorting [27,28]. S. cerevisiae is presently the preferred expression host and has been successfully used for the isolation of antibody leads against a wide range of target antigens. However, the existence of fungal type $\mathrm{N}$-glycans within the variable-region can still cause artifacts and have a negative impact on antibody selection [29]. Further development of the yeast antibody display system will require replacing fungal type $\mathrm{N}$-linked glycans with mammalian-type $\mathrm{N}$-glycans. With the uniform $\mathrm{N}$-glycan profile generated by humanized $P$. pastoris, the glycoengineered $P$. pastoris display system provides a unique opportunity to leverage variableregion glycosylation in mAb discovery. An antibody display library containing $\mathrm{N}$-linked glycosylation in variable-region can be rationally designed by introducing a consensus N-linked glycan motif (Asn-X-Ser or Thr, where $\mathrm{X} \neq$ Pro) throughout the CDRs. N-link glycosylation can also be generated by using random mutagenesis approaches. We postulate that an antibody variableregion glycosylation library constructed like this will be especially suitable for affinity maturation, where antibodies with increased affinity for antigen are selected. We demonstrate that by utilizing $P$. pastoris mating it is feasible to generate relatively large yeast antibody libraries from easily constructed small libraries of heavy and light chains. Future development of glycoengineered $P$. pastoris system will ultimately enable a unique expression host, streamlining discovery, optimization, and production.

\section{Conclusions}

The main purpose of this study is to investigate utilization of diploid P. pastoris strains for heterologous protein expression and to understand diploid strain stability in high-productivity fermentation. By using an anti-HER2 monoclonal antibody as a target protein, we demonstrate that recombinant protein production in both wild-type and glycoengineered $P$. pastoris diploids is stable and efficient using a nutrient rich shake flask cultivation. When the diploid strains were cultivated under bioreactor conditions, sporulation was observed. Still, both wild-type and glycoengineered $P$. pastoris diploids showed robust productivity and secreted recombinant antibody with high quality. We further demonstrate that diploid $P$. pastoris strains offer comparable protein productivity and $\mathrm{N}$-glycosylation profile to that of a haploid strain expressing the same antibody.

During manuscript preparation, the authors found two U.S. patent applications describing the use of Pichia pastoris diploids submitted by another group of researchers $[30,31]$. Still, to the best of our knowledge, this study reports for the first time a comprehensive characterization of recombinant protein expression and fermentation using diploid P. pastoris strains. Data presented here support the use of mating for various applications including strain consolidation, variable-region glycosylation antibody display library, and process optimization.

\section{Methods}

\section{Reagents \& construction of anti-HER2 mAb expression} plasmids

Escherichia coli strains TOP10 or XL10-Gold were used for recombinant DNA work. PNGase F, DNA restriction and DNA modification enzymes were obtained from New England BioLabs (Ipswich, MA). Figure 1 illustrates plasmid maps of anti-HER2 expression vectors used in this study. Anti-HER2 heavy and light chain genes (Herceptin ${ }^{\circledR}$ monograph, www.rochecanada.com) were codon optimized for $P$. pastoris expression and synthesized from GeneArt (Regensburg, Germany). Green fluorescent protein yEGFP3 [32] and red fluorescent protein mCherry [33] were codon optimized and synthesized from Genscript (Piscataway, NJ).

Plasmid pGLY10969 (Figure 1a) was a roll-in integration plasmid encoding the light chain of the anti-HER2 antibody and mCherry red fluorescent protein that targeted the URA6 locus in P. pastoris. The antibody light chain expression cassette used methanol inducible AOX1 promoter and TEF transcription terminator sequences. S. cerevisiae alpha-mating factor signal sequences were applied to light chain as secretion signal peptide. The RFP expression cassette used constitutive TEF promoter and AOX1 transcription terminator sequences. The selection of transformants used arsenic resistance (ARS) encoded by the $S$. cerevisiae ARR3 ORF under the control of the $P$. pastoris RPL10 promoter and $S$. cerevisiae CYC1 transcription terminator sequences. The plasmid further included a nucleic acid molecule for targeting the URA6 locus.

Plasmid pGLY10970 (Figure 1b) was a roll-in integration plasmid encoding the heavy chain of anti-HER2 antibody and yEGFP3 green fluorescent protein that targeted the URA6 locus in P. pastoris. The antibody heavy chain expression cassette used methanol inducible AOX1 promoter and TEF transcription terminator sequences. $S$. cerevisiae alpha-mating factor signal sequences were applied to heavy chain as secretion signal peptide. The GFP expression cassette used constitutive TEF promoter and AOX1 transcription terminator sequences. The selection of transformants used nourseothricin resistance encoded by the Streptomyces noursei nourseothricin acetyltransferase (NAT) ORF under the control of the Ashbya gossypii TEF1 promoter and Ashbya gossypii TEF1 terminator sequences. The plasmid 
further included a nucleic acid molecule for targeting the URA6 locus.

Plasmid pGLY6830 (Figure 1c) was a roll-in integration plasmid encoding both the light and heavy chains of anti-HER2 antibody that target the TRP2 locus in P. pastoris. Both the heavy and light chain expression cassettes used methanol inducible AOX1 promoter and AOX1 transcription terminator sequences. S. cerevisiae alphamating factor signal sequences were applied to both heavy and light chain as secretion signal peptide. For selecting transformants, the plasmid comprised an expression cassette encoding the Zeocin selection marker controlled by $S$. cerevisiae TEF promoter and S. cerevisiae $\mathrm{CYC} 1$ transcription terminator sequences. The plasmid further includes a nucleic acid molecule for targeting the TRP2 locus.

\section{Yeast strains}

Table 1 lists the yeast strains used in this study. All glycoengineered $P$. pastoris expression strains used were constructed from wild-type $P$. pastoris strain NRRLY11430 (Northern Regional Research Laboratories, Peoria, IL) using methods as described in $[7,11,13]$.

The starting GS2.0 strain for the mating construction of recombinant anti-HER2 expression was YGLY8292

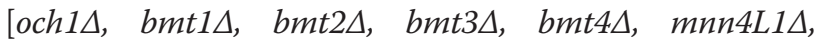

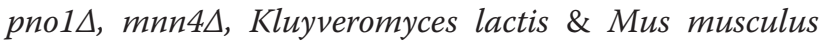
UDP-GlcNAc transporters, Trichoderma reesei $\alpha-1,2-$ MnsI]. Glycoproteins expressed from this strain lineage are decorated with Man5 glycans.

The starting GS5.0 glycoengineered strain for the construction of the recombinant anti-HER2 expression was YGLY8316 [24]. Glycoproteins expressed in this strain are decorated with biantennary complex, galactosylated (G2) glycans.

The plasmids encoding the light chain and heavy chain of the anti-HER2 antibody were linearized with SpeI to favor the integration at TRP2 or URA6 locus of P. pastoris genome and transformed into yeast by electroporation. Yeast strains YGLY27429 and YGLY27433 were generated by transforming pGLY10969, which encoded the light chain of anti-HER2 antibody and mCherry red fluorescent protein into $P$. pastoris wild-type strain NRRL-Y11430 and glycoengineered GS 2.0 strain YGLY8292, respectively. Yeast strains YGLY27430 and YGLY27434 were generated by transforming pGLY10970, which encoded the heavy chain of anti-HER2 antibody and GFP green fluorescent protein into wild-type strain NRRL-Y11430 and glycoengineered GS 2.0 strain YGLY8292, respectively.

Diploid yeast strain YGLY27431 was generated from the mating of YGLY27429 and YGLY27430; this strain contains $\mathrm{OCH} 1$ wild-type N-glycan structure. GS2.0 diploid yeast strain YGLY27435 was generated from the mating of YGLY27433 and YGLY27434. Haploid antiHER2 producing yeast strains YGLY27432 and YGLY27436 were obtained by double transformation of plasmids pGLY10969 and pGLY10979 into NRRLY11430 and YGLY8292, respectively. The strains comprised both anti-HER2 heavy and light chain expression cassettes and were used as anti-HER2 producing haploid control strains.

Yeast strain YGLY13979 [24] was generated by transforming pGLY6830, which encoded both heavy and light chains of anti-HER2 antibody, into the glycoengineered GS5.0 strain YGLY8316. The URA5 gene of the prototroph YGLY13979 was flanked by two lacZ repeats introduced during the strain construction procedure.

Strain YGLY13979 was counter-selected in the presence of 5-fluoroorotic acid (5-FOA) to produce the yeast strain YGLY19313 in which the URA5 gene was lost and only one copy of lacZ repeat remains in the chromosome. This rendered the strain auxotrophic for uracil. Afterwards, strain YGLY19313 was transformed with pGLY24 [34], a ARG3 knockout vector using URA5 as a selectable marker. This rendered the strain auxotrophic for arginine. Strain YGLY19853 was selected from the strains produced.

Diploid yeast strains YGLY19895 was generated from the mating of YGLY19313 and YGLY19853 using ARG3 and URA5 as selection markers. This strain, YGLY19895, is prototrophic and contains one copy of URA5 and ARG3 in its diploid genome. Strain YGLY19895 is considered to be an isogenic, homozygous diploid strain of YGLY13979.

\section{Mating and sporulation of $P$. Pastoris}

Strains were mated using modified methods similar to as described in [35]. In general, twenty $\mathrm{OD}_{600}$ of cells from each parental haploid strain were combined and spread evenly onto a $100 \mathrm{~mm}$ mating Petri dish $(0.5 \%$ sodium acetate, $1 \%$ potassium chloride, $1 \%$ glucose, $2 \%$ agar). For the OCH1 wild-type P. pastoris strains, the mating reaction was allowed to proceed at $25^{\circ} \mathrm{C}$ for 3 days. For the glycoengineered strains, the mating reaction condition was $25^{\circ} \mathrm{C}$ for 5 days. Cells were then struck out to single colonies on diploid selection media. Glycoengineered diploid strains were selected on YSD plate containing $0.2 \mathrm{mM}$ sodium arsenite and $25 \mu \mathrm{g} / \mathrm{ml}$ nourseothricin; OCH1 wild-type $P$. pastoris diploids were selected with $0.5 \mathrm{mM}$ sodium arsenite and $100 \mu \mathrm{g} / \mathrm{ml}$ nourseothricin.

The maximum mating efficiency for the $P$. pastoris strain tested was quantitatively determined using the filter method. In general, $1 \mathrm{OD}_{600}$ of haploid P. pastoris cells corresponded to around $10^{7}$ cells. Five $\mathrm{OD}_{600}$ of cells from each parental haploid strain were combined and collected on the membrane surface (MF- 
Millipore $^{\mathrm{TM}}$ HAWP, mixed cellulose esters, hydrophilic, $0.45 \mu \mathrm{m}$ pore, $47 \mathrm{~mm}$ diameter) using a vacuum filtration apparatus. The membrane was transferred cell side up to a $100 \mathrm{~mm}$ mating Petri dish. After 3 days, $25^{\circ} \mathrm{C}$ incubation (5 days for glycoengineered strains), cells were washed away from the membrane surface. The measured cell re-suspension OD is usually within a 1-2 fold range of initial starting $\mathrm{OD}$ (i.e. $10 \mathrm{OD}_{600}, 10^{8}$ cells), indicating that cells were not actively dividing on the mating membrane.

The mating efficiency was determined from the number of diploid colonies growing on serially diluted diploid selection plates divided by (i) $10^{8}$ (starting cell numbers) and then (ii) the "fold range" of cell resuspension OD. The "fold range" is a number usually between 1.5 and 2 . .

For the yeast display mating library construction, a

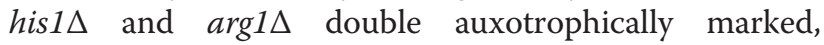
OCH1 wild-type $P$. pastoris strain was used as the host strain. The heavy chain and light chain libraries were transformed separately into the above $P$. pastoris host. Mating of heavy chain and light chain haploid libraries was conducted on an agar surface (without filter) using a $222 \mathrm{~mm} \times 222 \mathrm{~mm}$ Q-Trays Petri dish (Genetix Molecular Devices, Inc).

One-hundred $\mathrm{OD}_{600}$ of cells from each parental haploid strain were combined and evenly spread on the mating media agar containing $50 \mu \mathrm{g} / \mathrm{ml}$ histidine and arginine supplement. After 3 days, $25^{\circ} \mathrm{C}$ incubation, cells were washed away from the plate surface and the diploid antibody display library was selected in liquid minimal media without amino acids. About $5 \times 10^{6}$ diploid colonies were obtained after one mating reaction. The calculated mating efficiency here was around $0.25 \%$.

To initiate diploid sporulation, about $50 \mathrm{OD}_{600}$ of freshly patched diploids cells were resuspended in $10 \mathrm{~mL}$ liquid sporulation media $(0.5 \%$ sodium acetate, $1 \%$ potassium chloride, $1 \%$ glucose) in a $50 \mathrm{~mL}$ conical tube (initial cell density $=5 \mathrm{OD}_{600}$ ). The tube was incubated in a temperature-controlled shaker at $25^{\circ} \mathrm{C}$ and $200 \mathrm{rpm}$ agitation. A random spore analysis procedure [35] was used to confirm ascospore formation in a fermentation sample. Vegetative diploid cells were eliminated by diethyl ether extraction and, afterwards, the resuspended spores were serially diluted and plated on YSD plates.

Recombinant anti-HER2 antibody expression (shake-flask) Yeast strains were analyzed for anti-HER2 production through small scale expression trials in $300 \mathrm{~mL}$ of buffered $2 \%$ glycerol complex medium (Teknova, Hollister, CA) in 1 liter shake flasks. Cell inoculums were incubated at $24^{\circ} \mathrm{C}$ for 2 days at $200 \mathrm{rpm}$ (approximate $\mathrm{OD}_{600}=1$ to 5 ). Subsequently, the cells were pelleted by centrifugation (1474 $\mathrm{g}$ for $5 \mathrm{~min}$ ) and resuspended in $300 \mathrm{ml}$ of buffered $2 \%$ methanol-complex medium (BMMY) for induction of the AOX1 promoter. Pmt inhibitor PMTi4 in $100 \%$ methanol were added to the induction media to a final concentration of $1.6 \mu \mathrm{g} / \mathrm{mL}$ to minimize O-linked glycosylation [36]. The induction time was carried out at $24^{\circ} \mathrm{C}$ for 3 days with continual shaking at $200 \mathrm{rpm}$. The culture medium was cleared of yeast cells by centrifugation at $15000 \mathrm{~g}$ for $5 \mathrm{~min}$.

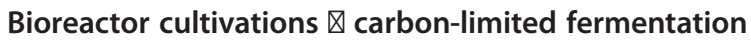

Bioreactor cultivations were performed in both 1 liter Fedbatch-pro, DASGIP BioTools or 3 liter Applikon glass bioreactors using the protocols described earlier [6]. In the present study, Martone was replaced with Soytone.

\section{Purification of anti-HER2 mAb}

Anti-HER2 mAb was purified using a one-step, 96-well format STREAMLINE rProtein A method as described in [37].

\section{SDS-polyacrylamide gel electrophoresis (SDS-PAGE)}

SDS-PAGE was carried out according to the Laemmli method with modified $4 \times$ non-reducing sample buffer (250 mM Tris, pH 6.8, 8\% SDS, 40\% v/v glycerol, $0.4 \%$ Bromophenol Blue sodium salt, $100 \mathrm{mM} \mathrm{N}$ ethylmaleimide) and $4 \times$ reducing sample buffer $(250 \mathrm{mM}$ Tris, pH 6.8, 8\% SDS, 40\% v/v glycerol, 0.4\% Bromophenol Blue sodium salt, $20 \% \mathrm{v} / \mathrm{v}$ b-mercaptoethanol). Gels were stained with $0.025 \%$ Coomassie Brilliant Blue R 250 in $7 \% \mathrm{v} / \mathrm{v}$ acetic acid, $40 \% \mathrm{v} / \mathrm{v}$ methanol and destained for $60 \mathrm{~min}$ in $10 \% \mathrm{v} / \mathrm{v}$ acetic acid.

\section{Binding kinetic analysis with her2 extracellular domain (ECD) protein}

Surface plasmon resonance measurements of binding affinity using BIAcore T100 (Biosystems \& ABI) were performed as described in [15].

\section{Liquid chromatography-mass spectrometry (LC-MS) analysis}

LC-MS analysis was performed on an Agilent 6520 QTOF mass spectrometer connected to an Agilent 1200 HPLC system (Agilent Technologies, Santa Clara, CA). Prior to LC-MS analysis, samples were deglycosylated by treatment with PNGase F (New England Biolabs, Ipswich, MA) at $37^{\circ} \mathrm{C}$ for 2 hours. A Mass PREP Micro Desalting column (Waters, Bedford, MA) was used to remove the salts and trap the proteins in all the experiments.

The mobile phases were $0.1 \%$ formic acid in $100 \%$ HPLC water (Buffer A) and 0.1\% formic acid in $90 \%$ acetonitrile/10\% HPLC water (Buffer B) (Fisher Scientific). 
The LC gradient started with $100 \%$ Buffer A at a flow rate of $1 \mathrm{ml} / \mathrm{min}$ for 2 minutes to remove salts in the sample, and the flow was diverted to the waste line. Bound proteins were eluted by running $100 \%$ Buffer B at a flow rate of $0.4 \mathrm{ml} / \mathrm{min}$ for 5 minutes, flow was delivered to the mass spectrometer for analysis. The column was equilibrated by flowing through Buffer $\mathrm{A}$ at $1 \mathrm{ml} / \mathrm{min}$ for $3 \mathrm{~min}$ utes. Mass spectra were recorded during protein elution at a range of $600-3000 \mathrm{~m} / \mathrm{z}$. The mass spectrometer was operated in positive mode, the $\mathrm{V}_{\text {cap }}$ was set at $4500 \mathrm{~V}$, and the gas flow rate was set at $13 \mathrm{~L} / \mathrm{min}$ at $350 \mathrm{oC}$. Data was analyzed using Agilent MassHunter Workstation Software (Agilent Technologies, Santa Clara, CA).

\section{Flow cytometry \& microscopy}

Flow cytometric analysis was performed using a BD LSRFortessa cell analyzer equipped with 488-nm and 561-nm excitation lasers. Manufacture recommended doublet discrimination gates in the dot plot with FSC and SSC were applied to ensure a population of single cells for analysis. The fluorescence intensities of the population were measured with a 530/30 nm optical filter for GFP and with a $610 / 20 \mathrm{~nm}$ optical filter for RFP in histograms. For each sample, 50,000 events were collected, and FlowJo software was used for the analysis of flow cytometry data.

Fluorescent microscopy observations were carried out using a Zeiss Axio Observer Z1 epifluorescence microscope equipped with a $1392 \times 1040$ pixel cooled CoolSNAP HQ2 CCD camera (Photometrics Corporation) and a $100 \times$ objective. False coloring was performed by capturing images with the appropriate colors (GFP filters: $436 / 20$ excitation \& 535/30 emission, RFP: $545 / 25$ $\& 605 / 70)$.

\section{Glycan characterization}

PNGase F, 2-aminobenzamide (2-AB) labeling and normal phase high performance liquid chromatography (HPLC) analysis of glycans were performed as described in [11].

\section{Protein A HPLC}

Fermentation titer of anti-HER2 IgG1 produced from $P$. pastoris was quantitatively determined using protein A high performance liquid chromatography (HPLC). Briefly, POROS ${ }^{\circledR} \mathrm{A}$ perfusion chromatography column was connected to an Agilent 1200 series HPLC with Diode Array Detector (Santa Clara, CA, USA). The pure $\mathrm{mAb}$ standard and sample were injected into a preequilibrated column at flow rate of $1 \mathrm{~mL} / \mathrm{min}$, followed by washing with $\mathrm{PBS}, \mathrm{pH}$ 7.4. Anti-HER2 $\mathrm{mAb}$ was eluted with elution buffer $\left(26 \mathrm{mM} \mathrm{H}_{3} \mathrm{PO}_{4}\right.$ in $\mathrm{PBS}, \mathrm{pH}$ 2.4) and monitored by UV absorbance at $280 \mathrm{~nm}$.
A linear standard curve was generated by plotting the integrated peak areas against the injected amounts of standards. The amount of recombinant IgG in injected samples was interpolated from the standard curve. Titer was calculated by dividing the amount of mAb by the injected sample volume.

\section{Abbreviations}

mAb: Monoclonal antibodies; ARS: Arsenic resistance; NAT: Nourseothricin resistance; RFP: Red fluorescent protein; GFP: Green fuorescent protein; CPCR: Colony PCR; WCW: Wet cell weight.

\section{Competing interests}

The authors declare competing financial interests.

\section{Authors' contributions}

M.T.C., T.A.S., and B.K.C. conceived of the ideas implemented in this study. M. T.C. designed and carried out the molecular biology experiments. B.K.C. supervised the project. M.T.C., T.A.S., and B.K.C. performed data analysis and wrote the paper. M.T.C. and S.L. carried out the flow cytometry assay. I.S. carried out the 3 Liter bioreactor cultivations and participated in HPLC analysis. D.A carried out the protein A purification and participated in HPLC analysis. All authors read and approved the final manuscript.

\section{Acknowledgements}

The authors would like to express their gratitude to Kevin Johnson of MRL Boston for his assistance of carrying out the flow cytometry assay; Dongxing Zha and Nga Rewa Houston-Cummings for the construction of YGLY13979 GS5.0 anti-HER2 producing yeast strain; Stephen Hamilton for the development of the arsenic resistance (ARS) marker in P. pastoris; Bianka Prinz for the design and construction of CDR3 heavy and light chain variant haploid libraries. We thank Juergen Nett and Robert Davidson for discussions, and Khanita Karaveg, Heather Lynaugh, Nathan Sharkey, and Seemab Shaikh for their technical assistance.

Received: 22 December 2011 Accepted: 16 June 2012 Published: 2 July 2012

\section{References}

1. Macauley-Patrick S, Fazenda ML, McNeil B, Harvey LM: Heterologous protein production using the Pichia pastoris expression system. Yeast 2005, 22:249-270.

2. Werten MW, van den Bosch TJ, Wind RD, Mooibroek H, de Wolf FA: High-yield secretion of recombinant gelatins by Pichia pastoris. Yeast 1999, 15:1087-1096.

3. Gurramkonda C, Polez S, Skoko N, Adnan A, Gabel T, Chugh D, Swaminathan S, Khanna N, Tisminetzky S, Rinas U: Application of simple fed-batch technique to high-level secretory production of insulin precursor using Pichia pastoris with subsequent purification and conversion to human insulin. Microb Cell Fact 2010, 9:31.

4. Barnard GC, Kull AR, Sharkey NS, Shaikh SS, Rittenhour AM, Burnina I, Jiang Y, Li F, Lynaugh H, Mitchell T, et al: High-throughput screening and selection of yeast cell lines expressing monoclonal antibodies. J Ind Microbiol Biotechnol 2010, 37:961-971.

5. Ye J, Ly J, Watts K, Hsu A, Walker A, McLaughlin K, Berdichevsky M, Prinz B, Sean Kersey D, D'Anjou M, et al: Optimization of a glycoengineered Pichia pastoris cultivation process for commercial antibody production. Biotechnol Prog 2011, 27(6):1744-1750.

6. Potgieter TI, Cukan M, Drummond JE, Houston-Cummings NR, Jiang Y, Li F, Lynaugh H, Mallem M, McKelvey TW, Mitchell T, et al: Production of monoclonal antibodies by glycoengineered Pichia pastoris. J Biotechnol 2009, 139:318-325.

7. Choi BK, Bobrowicz B, Davidson R, Hamilton S, Kung DH, Li H, Miele RG, Nett JH, Wildt S, Gerngross C: Use of combinatorial genetic libraries to humanize N-linked glycosylation in the yeast Pichiapastoris. Proc Natl Acad Sci U S A 2003, 100:5022-5027.

8. Bobrowicz P, Davidson RC, Li H, Potgieter TI, Nett JH, Hamilton SR, Stadheim TA, Miele RG, Bobrowicz B, Mitchell T, et al: Engineering of an artificial glycosylation pathway blocked in core oligosaccharide assembly in the 
yeast Pichia pastoris: production of complex humanized glycoproteins with terminal galactose. Glycobiology 2004, 14:757-766.

9. Davidson RC, Nett JH, Renfer E, Li H, Stadheim TA, Miller BJ, Miele RG, Hamilton SR, Choi BK, Mitchell TI, et al: Functional analysis of the ALG3 gene encoding the Dol-P-Man: Man5GIcNAc2-PP-Dol mannosyltransferase enzyme of P. pastoris. Glycobiology 2004, 14:399-407.

10. Wildt $\mathrm{S}$, Gerngross TU: The humanization of $\mathrm{N}$-glycosylation pathways in yeast. Nat Rev Microbiol 2005, 3:119-128.

11. Hamilton SR, Davidson RC, Sethuraman N, Nett JH, Jiang Y, Rios S, Bobrowicz P, Stadheim TA, Li H, Choi BK, et al: Humanization of yeast to produce complex terminally sialylated glycoproteins. Science 2006, 313:1441-1443.

12. Hamilton SR, Gerngross TU: Glycosylation engineering in yeast: the advent of fully humanized yeast. Curr Opin Biotechnol 2007, 18:387-392.

13. Nett JH, Stadheim TA, Li H, Bobrowicz P, Hamilton SR, Davidson RC, Choi BK, Mitchell T, Bobrowicz B, Rittenhour A, et al: A combinatorial genetic library approach to target heterologous glycosylation enzymes to the endoplasmic reticulum or the Golgi apparatus of Pichia pastoris. Yeast 2011, 28:237-252.

14. Li H, Sethuraman N, Stadheim TA, Zha D, Prinz B, Ballew N, Bobrowicz P, Choi BK, Cook WJ, Cukan M, et al: Optimization of humanized lgGs in glycoengineered Pichia pastoris. Nat Biotechnol 2006, 24:210-215.

15. Zhang N, Liu L, Dumitru CA: Glycoengineered Pichia produced anti-HER2 is comparable to trastuzumab in preclinical study. mAbs 2011, 3:289-298.

16. Nett JH, Gomathinayagam S, Hamilton SR, Gong B, Davidson RC, Du M, Hopkins D, Mitchell T, Mallem MR, Nylen A, et al: Optimization of erythropoietin production with controlled glycosylation-PEGylated erythropoietin produced in glycoengineered Pichia pastoris. J Biotechnol 2011, 157(1):198-206.

17. Albers $E$, Larsson C: A comparison of stress tolerance in $Y P D$ and industrial lignocellulose-based medium among industrial and laboratory yeast strains. J Ind Microbiol Biotechnol 2009, 36:1085-1091.

18. Garay-Arroyo A, Covarrubias AA, Clark I, Nino I, Gosset G, Martinez A: Response to different environmental stress conditions of industrial and laboratory Saccharomyces cerevisiae strains. Appl Microbiol Biotechnol 2004, 63:734-741.

19. Hashimoto S, Aritomi K, Minohara T, Nishizawa Y, Hoshida H, Kashiwagi S, Akada R: Direct mating between diploid sake strains of Saccharomyces cerevisiae. Appl Microbiol Biotechnol 2006, 69:689-696.

20. Golemis EA, Khazak V: Alternative yeast two-hybrid systems. The interaction trap and interaction mating. Methods Mol Biol 1997, 63:197-218

21. Weaver-Feldhaus JM, Lou J, Coleman JR, Siegel RW, Marks JD, Feldhaus MJ: Yeast mating for combinatorial Fab library generation and surface display. FEBS Lett 2004, 564:24-34.

22. Cregg JM: Genetics of methylotrophic yeasts. In Proceedings of the fifth international symposium on microbial growth on $\mathrm{Cl}$ compounds. The Netherlands: Martinus Nijhoff Publishers, Dordrecht; 1987.

23. Lee BN, Elion EA: The MAPKKK Ste11 regulates vegetative growth through a kinase cascade of shared signaling components. Proc Natl Acad Sci U S A 1999, 96:12679-12684.

24. Zha D: HER2 Antibody Compositions. US Patent Application Number US2010/ 025211; 2010.

25. Kassir Y, Granot D, Simchen G: IME1, a positive regulator gene of meiosis in S. cerevisiae. Cell 1988, 52:853-862.

26. Vershon AK, Pierce M: Transcriptional regulation of meiosis in yeast. Curr Opin Cell Biol 2000, 12:334-339.

27. Feldhaus MJ, Siegel RW, Opresko LK, Coleman JR, Feldhaus JM, Yeung YA, Cochran JR, Heinzelman P, Colby D, Swers J, et al: Flow-cytometric isolation of human antibodies from a nonimmune Saccharomyces cerevisiae surface display library. Nat Biotechnol 2003, 21:163-170.

28. Boder ET, Midelfort KS, Wittrup KD: Directed evolution of antibody fragments with monovalent femtomolar antigen-binding affinity. Proc Natl Acad Sci U S A 2000, 97:10701-10705.

29. Gala FA, Morrison SL: V region carbohydrate and antibody expression. J Immunol 2004, 172:5489-5494.

30. Cregg JM, Latham J, Litton M, Schatzman R, II T: Methods of synthesizing heteromultimeric polypeptides in yeast using a haploid mating strategy. US Patent Application Number US2011/0183402 A1; 2011.
31. Cregg JM, Latham J, Litton M, Schatzman R, II T: Methods of synthesizing heteromultimeric polypeptides in yeast using a haploid mating strategy. US Patent Number US2008/0003643 A1; 2008.

32. Cormack B: Green fluorescent protein as a reporter of transcription and protein localization in fungi. Curr Opin Microbiol 1998, 1:406-410.

33. Shaner NC, Campbell RE, Steinbach PA, Giepmans BN, Palmer AE, Tsien RY: Improved monomeric red, orange and yellow fluorescent proteins derived from Discosoma sp. red fluorescent protein. Nat Biotechnol 2004, 22:1567-1572

34. Nett JH, Hodel N, Rausch S, Wildt S: Cloning and disruption of the Pichia pastoris ARG1, ARG2, ARG3, HIS1, HIS2, HIS5, HIS6 genes and their use as auxotrophic markers. Yeast 2005, 22:295-304.

35. Cregg J (Ed): Pichia Protocols. 2nd edition. Totowa, NJ: Humana Press, Inc; 2007.

36. Ranjit D, Lihu Y: Efficient production of heterologous proteins using mannosyl transferase inhibitors. US Patent Application Number US2009/044297; 2009.

37. Jiang Y, Li F, Zha D, Potgieter TI, Mitchell T, Moore R, Cukan M, Houston-Cummings NR, Nylen A, Drummond JE, et al: Purification process development of a recombinant monoclonal antibody expressed in glycoengineered Pichia pastoris. Protein Expr Purif 2011, 76:7-14.

doi:10.1186/1475-2859-11-91

Cite this article as: Chen et al:: Generation of diploid Pichia pastoris strains by mating and their application for recombinant protein production. Microbial Cell Factories 2012 11:91.

\section{Submit your next manuscript to BioMed Central and take full advantage of:}

- Convenient online submission

- Thorough peer review

- No space constraints or color figure charges

- Immediate publication on acceptance

- Inclusion in PubMed, CAS, Scopus and Google Scholar

- Research which is freely available for redistribution 